\title{
Article \\ The Association between Peri-Transplant RBC Transfusion and Graft Failure after Kidney Transplantation: A Nationwide Cohort Study
}

\author{
Kyungho Lee ${ }^{1,+}+\mathbb{D}$, Seohee Lee ${ }^{2,+}$, Eun Jin Jang ${ }^{3}$, Ga Hee Kim ${ }^{4}$, Seokha Yoo ${ }^{2} \mathbb{D}$, Minkyoo Lee ${ }^{2}$, \\ Hye Ryoun Jang ${ }^{1, *, \ddagger}$ and Ho Geol Ryu ${ }^{2, *, \ddagger}$
}

1 Division of Nephrology, Department of Medicine, Samsung Medical Center, Sungkyunkwan University School of Medicine, Seoul 06351, Korea; kidney.kh@gmail.com

2 Department of Anesthesiology and Pain Medicine, Seoul National University Hospital, Seoul National University College of Medicine, Seoul 03080, Korea; leesen34@gmail.com (S.L.); muroki22@gmail.com (S.Y.); 2016.real@gmail.com (M.L.)

3 Department of Information Statistics, Andong National University, Andong 36729, Korea; jejstat@gmail.com

4 Department of Statistics, Kyungpook National University, Daegu 41566, Korea; genius9105@naver.com

* Correspondence: shinehr@skku.edu (H.R.J.); hogeol@gmail.com (H.G.R.); Tel.: +82-2-3410-0782 (H.R.J.); +82-2-2072-2065 (H.G.R.)

+ Kyungho Lee and Seohee Lee have equally contributed to this study as co-first authors.

$\ddagger$ Hye Ryoun Jang and Ho Geol Ryu have equally contributed to this study as co-corresponding authors.

check for updates

Citation: Lee, K.; Lee, S.; Jang, E.J.; Kim, G.H.; Yoo, S.; Lee, M.; Jang, H.R.; Ryu, H.G. The Association between Peri-Transplant RBC Transfusion and Graft Failure after Kidney Transplantation: A Nationwide Cohort Study. J. Clin. Med. 2021, 10, 3750. https://doi.org/10.3390/ jcm10163750

Academic Editor: Adrian Covic

Received: 20 June 2021

Accepted: 18 August 2021

Published: 23 August 2021

Publisher's Note: MDPI stays neutral with regard to jurisdictional claims in published maps and institutional affiliations.

Copyright: (c) 2021 by the authors. Licensee MDPI, Basel, Switzerland. This article is an open access article distributed under the terms and conditions of the Creative Commons Attribution (CC BY) license (https:/ / creativecommons.org/licenses/by/ $4.0 /)$.
Abstract: Background: Patients undergoing kidney transplantation (KT) often receive red blood cell (RBC) transfusion during admission for KT which may increase the risk of allosensitization. The association between peri-transplant RBC transfusion and graft survival was evaluated using a nationwide cohort. Methods: This retrospective study analyzed 13,871 patients who underwent KT in Korea between 2007 and 2015. The outcomes were graft failure rate and overall patient survival depending on the amount of RBC transfusion. Results: The overall graft failure rate was $15.5 \%$. Compared to the graft failure rate of $13.5 \%$ in the no transfusion group, the graft failure rate was $15.4 \%$ in the $1-2$ units group (sHR 1.06 (95\% CI 0.97-1.17), $p=0.216$ ), 21.4\% in the $3-5$ units group (sHR $1.39(1.21-1.61), p<0.001)$, and $35.3 \%$ in the 6 or more units group (sHR $2.20(1.70-2.85), p<0.001)$. The overall survival rate was $97.5 \%$ in the no transfusion group, compared to $95.9 \%$ in the $1-2$ units group (HR 1.50 (1.22-1.83), $p<0.001), 92.0 \%$ in the 3-5 units group (HR 2.43 (1.87-3.15), $p<0.001$ ), and $67.5 \%$ in the 6 or more units group (HR 6.81 (5.03-9.22), $p<0.001)$. Conclusions: Peri-transplant $\mathrm{RBC}$ transfusion was independently associated with the increased risk of renal allograft failure and death in KT patients.

Keywords: kidney transplantation; red blood cells; transfusion; graft failure; survival

\section{Introductions}

Kidney transplantation (KT) is the treatment of choice for end-stage renal disease (ESRD) with clear advantages over renal replacement therapy in survival and quality of life [1]. Graft survival after KT has significantly improved with recent 5-year graft survival rates ranging between $75 \%$ and $90 \%$ [1-3]. However, there seems to be room for improvement in long-term graft survival rates [4].

Blood transfusion prior to KT was common practice [5] until the early 1980s with intentions to improve graft survival rates through immunosuppression by transfused white blood cells [6]. Following increased graft survival due to improved human leukocyte antigen (HLA) matching and more effective immunosuppressive agents, the benefit of peritransplant transfusion in KT became insignificant [7]. In the 1990s, most KT centers moved away from routine pre-transplant blood transfusion, especially for immunosuppression purposes [8]. In addition, anemia in patients undergoing KT became less frequent with 
the introduction of erythropoiesis-stimulating agents (ESAs), which are now universally used [9]. Furthermore, blood transfusion in KT recipients can lead to sensitization, which may increase the possibility of antibody formation that may attack the allograft [10].

Recent data show that $52-64 \%$ of patients undergoing KT still receive blood transfusion $[10,11]$. However, the impact of peri-transplant transfusion on the renal allograft outcome remains unclear. Studies evaluating the relationship between peri-transplant transfusion and the renal allograft outcome have shown conflicting results [10,11]. To evaluate the association between peri-transplant red blood cell (RBC) transfusion and graft survival, a nationwide cohort study using the National Healthcare Insurance Service (NHIS) database was conducted.

\section{Materials and Methods}

This study was a retrospective cohort study and the study protocol conformed to the ethical guidelines of the 1975 Declaration of Helsinki as reflected in a priori approval by the Institutional Review Board of Seoul National University Hospital (1708-061-877). The clinical and research activities reported are consistent with the Principles of the Declaration of Istanbul as outlined in the 'Declaration of Istanbul on Organ Trafficking and Transplant Tourism'.

\subsection{Data Source and Study Population}

The NHIS database contains all claims data for more than $97 \%$ of the population who are covered under the National Healthcare Insurance (NHI) program and the Medical Aid program in Korea. The NHIS database is provided to researchers after de-identification for research purposes and generation of real-world evidence.

Adult patients (age $\geq 19$ ) who received KT between 2007 and 2015 were identified from the NHIS database by searching the NHI procedure code for KT during hospitalization. Patients with simultaneous NHI procedure codes for other solid organ transplantations such as pancreas, liver, or heart transplantation during the same admission for KT were excluded. After identification of adult KT recipients, underlying comorbidities including hypertension, diabetes mellitus, coronary artery disease, and cardiovascular disease were extracted from the database using ICD-10 (International Classification of Diseases, 10th revision) codes. To adjust for the severity of illness, the Elixhauser Comorbidity Index, derived from 30 disease entities using ICD-10 codes and shown to correlate with hospital mortality, was used as a covariate.

The two outcomes of interests were allograft failure (not including death with function) and all-cause mortality. Allograft failure was detected by NHI procedure codes for dialysis or retransplantation. Long-term mortality was detected when healthcare coverage by the NHI was terminated based on automatically reported death certificates to the NHI. In-hospital mortality, intensive care unit (ICU) length of stay, and hospital length of stay were also extracted. To analyze immunologic risk factors, the following data were extracted from the database: presence of donor specific antibody (DSA; defined by NHI procedure code for desensitization therapy), regimens of induction treatment, delayed graft function (DGF; defined as the requirement for dialysis within the first week after transplantation), and acute allograft rejection (defined by NHI procedure code for anti-rejection therapy). The data on perioperative bleeding complications were obtained from the database using the NHI procedure codes for angiographic embolization and bleeding control operation.

\subsection{Statistical Analysis}

Patient characteristics were compared according to the number of transfused packed RBC units using the chi-square test or Fisher's exact test.

A competing-risk analysis model (Fine and Gray model) was used considering death with functioning graft as a competing event to investigate the association between transfused RBC units and graft failure with adjustment of multiple covariates. The competingrisk analysis results were presented as a subdistribution hazard ratio (sHR) with a $95 \%$ 
confidence interval (CI). To analyze the association between transfused RBC units and mortality, a Cox proportional hazards model was used and the results were presented as a hazard ratio (HR) with a $95 \% \mathrm{CI}$.

The Kaplan-Meier survival curve after KT depends on the number of transfused RBC units and performed the log-rank test to compare the survival curve. All analyses were performed using SAS 9.4 (SAS Institute, Cary, NC, USA). Results were considered statistically significant when two-sided $p$-values were less than 0.05 .

\section{Results}

A total of 13,781 KTs were performed from 2007 to 2016 in Korea. Patient and center characteristics are presented in Table 1. All patients were divided into four groups depending on the number of transfused packed RBC units during the hospitalization period for KT. A total of 6594 patients did not receive $\mathrm{RBC}$ transfusion during the perioperative period. Of the patients who received transfusion, 5687 patients received 1-2 units, 1212 patients received 3-5 units, and 378 patients received 6 units or more. The proportions of positive-DSA were significantly higher in patients who received larger amounts of RBC transfusion (Table 1).

Table 1. Patient characteristics according to the amount of RBC transfusion.

\begin{tabular}{|c|c|c|c|c|c|c|}
\hline & \multirow[b]{2}{*}{$\begin{array}{c}\text { Total } \\
(n=13,871)\end{array}$} & \multicolumn{4}{|c|}{ Units of Transfused Red Blood Cells } & \multirow[b]{2}{*}{$p$-Value } \\
\hline & & $\begin{array}{c}0 \text { Units } \\
(n=6594)\end{array}$ & $\begin{array}{l}\text { 1-2 Units } \\
(n=5687)\end{array}$ & $\begin{array}{l}3-5 \text { Units } \\
(n=1212)\end{array}$ & $\begin{array}{l}6 \text { or More Units } \\
\quad(n=378)\end{array}$ & \\
\hline \multicolumn{7}{|l|}{ Age } \\
\hline $19-49$ & $7524(54.2)$ & $3693(56.0)$ & $3064(53.9)$ & $614(50.7)$ & $152(40.2)$ & $<0.001$ \\
\hline $50-59$ & $4502(32.5)$ & $2102(31.9)$ & $1845(32.4)$ & 407 (33.6) & $148(39.2)$ & \\
\hline$\geq 60$ & $1846(13.3)$ & $799(12.1)$ & $778(13.7)$ & $191(15.8)$ & $78(20.6)$ & \\
\hline \multicolumn{7}{|l|}{ Sex } \\
\hline Female & $5642(40.7)$ & $2286(34.7)$ & $2600(45.7)$ & $571(47.1)$ & $185(48.9)$ & \\
\hline Male & $8229(59.3)$ & $4308(65.3)$ & $3087(54.3)$ & $641(52.9)$ & $193(51.1)$ & $<0.001$ \\
\hline \multicolumn{7}{|l|}{ Comorbidities } \\
\hline Hypertension & $6765(48.8)$ & $3281(49.8)$ & $2709(47.6)$ & $581(47.9)$ & $194(51.3)$ & 0.067 \\
\hline Diabetes mellitus & $3879(28.0)$ & $1798(27.3)$ & $1554(27.3)$ & $393(32.4)$ & $134(35.4)$ & $<0.001$ \\
\hline Coronary artery disease & $2848(20.5)$ & $1395(21.2)$ & $1076(18.9)$ & $269(22.2)$ & $108(28.6)$ & $<0.001$ \\
\hline Cerebrovascular disease & $800(5.8)$ & $339(5.1)$ & $342(6.0)$ & $81(6.7)$ & $38(10.1)$ & 0.002 \\
\hline Deceased donor transplantation & $3077(22.2)$ & $1153(17.5)$ & $1363(24.0)$ & $379(31.3)$ & $182(48.1)$ & $<0.001$ \\
\hline Positive donor specific antibody & $2084(15)$ & $624(9.5)$ & $959(16.9)$ & $336(27.7)$ & $165(43.7)$ & $<0.001$ \\
\hline \multicolumn{7}{|l|}{ Induction treatment } \\
\hline Methylprednisolone & $481(3.5)$ & $250(3.8)$ & $187(3.3)$ & $36(3.0)$ & $8(2.1)$ & $<0.001$ \\
\hline Anti-thymocyte globulin & $1897(13.7)$ & $829(12.6)$ & $745(13.1)$ & $226(18.6)$ & $97(25.7)$ & \\
\hline Basiliximab & $11,405(82.2)$ & $5479(83.1)$ & $4711(82.8)$ & $945(78.0)$ & $270(71.4)$ & \\
\hline Rituximab & $88(0.6)$ & $36(0.5)$ & $44(0.8)$ & $5(0.4)$ & $3(0.8)$ & \\
\hline Acute rejection & $1096(7.9)$ & $571(8.7)$ & $412(7.2)$ & $94(7.8)$ & $19(5.0)$ & 0.005 \\
\hline Delayed graft function & $253(1.8)$ & $18(0.3)$ & $60(1.1)$ & $48(4.0)$ & $127(33.6)$ & $<0.001$ \\
\hline Elixhauser Comorbidity Index & $14.1(8.6)$ & $14.1(8.4)$ & $13.7(8.6)$ & $15.0(9.0)$ & $17.5(9.8)$ & $<0.001$ \\
\hline
\end{tabular}

Data are presented as a number (percentage) or mean (standard deviation).

The overall graft failure rates at 1, 3, 5, and 7 years after KT were $7.0 \%(811 / 11,665)$, $14.1 \%(1150 / 8163), 18.3 \%(904 / 4942)$, and 21.3\% (507/2381), respectively. There was a positive correlation between the number of RBC transfusions and graft failure rates at various time points after KT (Table 2).

The competing-risk analysis for graft failure treating death with functioning graft as a competing event showed that the risk of graft failure was significantly higher in patients who received larger amounts RBC transfusion. Patients who received 6 or more units (sHR 2.20 (95\% CI: 1.70, 2.85)) and patients who received 3-5 units (sHR 1.39 (95\% CI: 1.21, 1.61)) showed higher risk of graft failure compared to the patients who did not receive transfusion. The risk of graft failure after KT in patients who received 1-2 units was comparable to patients who did not receive transfusion (sHR 1.06 (95\% CI: 0.97, 1.17)) (Table 3). Deceased donor KT, DSA positivity, acute rejection, and delayed graft function were also independently associated with a higher risk of graft failure. Patients who received 
induction therapy with anti-thymocyte globulin or basiliximab showed a higher risk of graft failure compared to patients who only received methylprednisolone. Death censored graft survival rates according to the amount of RBC transfusion are presented in Figure 1 $(p<0.001)$.

Table 2. Graft failure rate, in-hospital mortality, and perioperative bleeding events according to the amount of transfusion.

\begin{tabular}{|c|c|c|c|c|c|c|}
\hline & \multicolumn{6}{|c|}{ Units of Transfused Red Blood Cells } \\
\hline & $\begin{array}{l}\text { 1otal } \\
(n=13,871)\end{array}$ & $\begin{array}{c}0 \text { Units } \\
(n=6594)\end{array}$ & $\begin{array}{l}\text { 1-2 Units } \\
(n=5687)\end{array}$ & $\begin{array}{l}\text { 3-5 Units } \\
(n=1212)\end{array}$ & $\begin{array}{l}6 \text { or More Units } \\
\quad(n=378)\end{array}$ & $p$-Value \\
\hline 1-year graft failure rate & $\begin{array}{c}811 / 11,66 \\
(7.0)\end{array}$ & $\begin{array}{c}307 / 5477 \\
(5.6)\end{array}$ & $\begin{array}{l}313 / 4870 \\
(6.4)\end{array}$ & $\begin{array}{c}115 / 1057 \\
(10.9)\end{array}$ & $\begin{array}{c}76 / 261 \\
(29.1)\end{array}$ & $<0.001$ \\
\hline 3-year graft failure rate & $\begin{array}{c}1150 / 8163 \\
(14.1)\end{array}$ & $\begin{array}{l}476 / 3708 \\
(12.8)\end{array}$ & $\begin{array}{l}461 / 3498 \\
(13.2)\end{array}$ & $\begin{array}{c}149 / 768 \\
(19.4)\end{array}$ & $\begin{array}{c}64 / 189 \\
(33.9)\end{array}$ & $<0.001$ \\
\hline 5-year graft failure rate & $\begin{array}{c}904 / 4942 \\
(18.3)\end{array}$ & $\begin{array}{c}362 / 2176 \\
(16.6)\end{array}$ & $\begin{array}{c}376 / 2168 \\
(17.3)\end{array}$ & $\begin{array}{c}127 / 494 \\
(25.7)\end{array}$ & $\begin{array}{c}39 / 104 \\
(37.5)\end{array}$ & $<0.001$ \\
\hline 7-year graft failure rate & $\begin{array}{c}507 / 2381 \\
(21.3)\end{array}$ & $\begin{array}{l}221 / 1081 \\
(20.4)\end{array}$ & $\begin{array}{l}205 / 1040 \\
(19.7)\end{array}$ & $\begin{array}{c}61 / 207 \\
(29.5)\end{array}$ & $\begin{array}{l}20 / 53 \\
(37.7)\end{array}$ & $<0.001$ \\
\hline In-hospital mortality & $\begin{array}{c}113 / 13,871 \\
(0.8)\end{array}$ & $\begin{array}{c}5 / 6594 \\
(0.1)\end{array}$ & $\begin{array}{c}16 / 5689 \\
(0.3)\end{array}$ & $\begin{array}{c}14 / 1212 \\
(1.2)\end{array}$ & $\begin{array}{c}78 / 376 \\
(20.6)\end{array}$ & $<0.001$ \\
\hline Bleeding control operation & $\begin{array}{c}331 / 13,871 \\
(2.4)\end{array}$ & $\begin{array}{c}26 / 6594 \\
(0.4)\end{array}$ & $\begin{array}{c}94 / 5687 \\
(1.7)\end{array}$ & $\begin{array}{c}95 / 1212 \\
(7.8)\end{array}$ & $\begin{array}{c}116 / 378 \\
(30.7)\end{array}$ & $<0.001$ \\
\hline Angiographic embolization & $\begin{array}{c}81 / 13,871 \\
(0.6)\end{array}$ & $\begin{array}{c}5 / 6594 \\
(0.1)\end{array}$ & $\begin{array}{c}21 / 5687 \\
(0.4)\end{array}$ & $\begin{array}{c}16 / 1212 \\
(1.3)\end{array}$ & $\begin{array}{c}39 / 378 \\
(10.3)\end{array}$ & $<0.001$ \\
\hline
\end{tabular}

Data are presented as a number (percentage).

Table 3. Competing-risk analysis for graft failure (competing event of death with functioning graft).

\begin{tabular}{|c|c|c|c|c|c|c|}
\hline & \multicolumn{3}{|c|}{ Univariate Analyses } & \multicolumn{3}{|c|}{ Multivariable Analyses } \\
\hline & $\begin{array}{c}\text { Hazard } \\
\text { Ratio }\end{array}$ & $95 \% \mathrm{CI}$ & $p$-Value & $\begin{array}{c}\text { Hazard } \\
\text { Ratio }\end{array}$ & $95 \% \mathrm{CI}$ & $p$-Value \\
\hline \multicolumn{7}{|l|}{ Age } \\
\hline \multicolumn{7}{|l|}{$19-49$} \\
\hline $50-59$ & 1.09 & $0.99,1.20$ & 0.074 & 1.08 & $0.98,1.18$ & 0.132 \\
\hline$\geq 60$ & 1.09 & $0.96,1.25$. & 0.197 & 1.04 & $0.90,1.19$ & 0.620 \\
\hline \multicolumn{7}{|l|}{ Sex } \\
\hline \multicolumn{7}{|l|}{ Female } \\
\hline Male & 0.96 & $0.88,1.04$ & 0.303 & 0.97 & $0.89,1.06$ & 0.549 \\
\hline \multicolumn{7}{|l|}{ Living donor kidney transplantation } \\
\hline Deceased donor kidney transplantation & 1.81 & $1.66,1.98$. & $<0.001$ & 1.68 & $1.53,1.85$ & $<0.001$ \\
\hline \multicolumn{7}{|l|}{ Donor specific antibody } \\
\hline \multicolumn{7}{|l|}{ Absent } \\
\hline Present & 1.28 & $1.13,1.44$. & $<0.001$ & 1.17 & $1.03,1.34$ & 0.017 \\
\hline \multicolumn{7}{|l|}{ Induction treatment } \\
\hline \multicolumn{7}{|l|}{ Methylprednisolone (reference) } \\
\hline Anti-thymocyte globulin & 2.67 & $2.01,3.55$. & $<0.001$ & 2.02 & $1.52,2.68$ & $<0.001$ \\
\hline Basiliximab & 1.74 & $1.33,2.27$ & $<0.001$ & 1.42 & $1.09,1.84$ & 0.009 \\
\hline Rituximab & 3.17 & $1.27,7.93$ & 0.014 & 2.74 & $1.12,6.75$ & 0.028 \\
\hline \multicolumn{7}{|l|}{ Acute rejection } \\
\hline \multicolumn{7}{|l|}{ Absent } \\
\hline Present & 2.93 & $2.65,3.25$. & $<0.001$ & 2.97 & $2.67,3.31$ & $<0.001$ \\
\hline \multicolumn{7}{|l|}{ Delayed graft function } \\
\hline \multicolumn{7}{|l|}{ Absent } \\
\hline Present & 3.24 & $2.49,4.20$ & $<0.001$ & 1.94 & $1.44,2.62$ & $<0.001$ \\
\hline \multicolumn{7}{|l|}{ Transfused red blood cell units } \\
\hline \multicolumn{7}{|l|}{ None } \\
\hline $1-2$ units & 1.09 & $1.00,1.20$. & 0.061 & 1.06 & $0.97,1.17$ & 0.216 \\
\hline $3-5$ units & 1.57 & $1.37,1.81$ & $<0.001$ & 1.39 & $1.21,1.61$ & $<0.001$ \\
\hline 6 units or more & 3.36 & $2.69,4.20$ & $<0.001$ & 2.20 & $1.70,2.85$ & $<0.001$ \\
\hline Elixhauser Comorbidity Index & 1.00 & $1.00,1.01$ & 0.151 & 1.00 & $1.00,1.01$ & 0.511 \\
\hline
\end{tabular}

Abbreviation: CI, confidence interval. The subdistribution hazard of ESRD (end-stage renal disease) was used for the hazard ratio (competing event for death with functioning graft). 


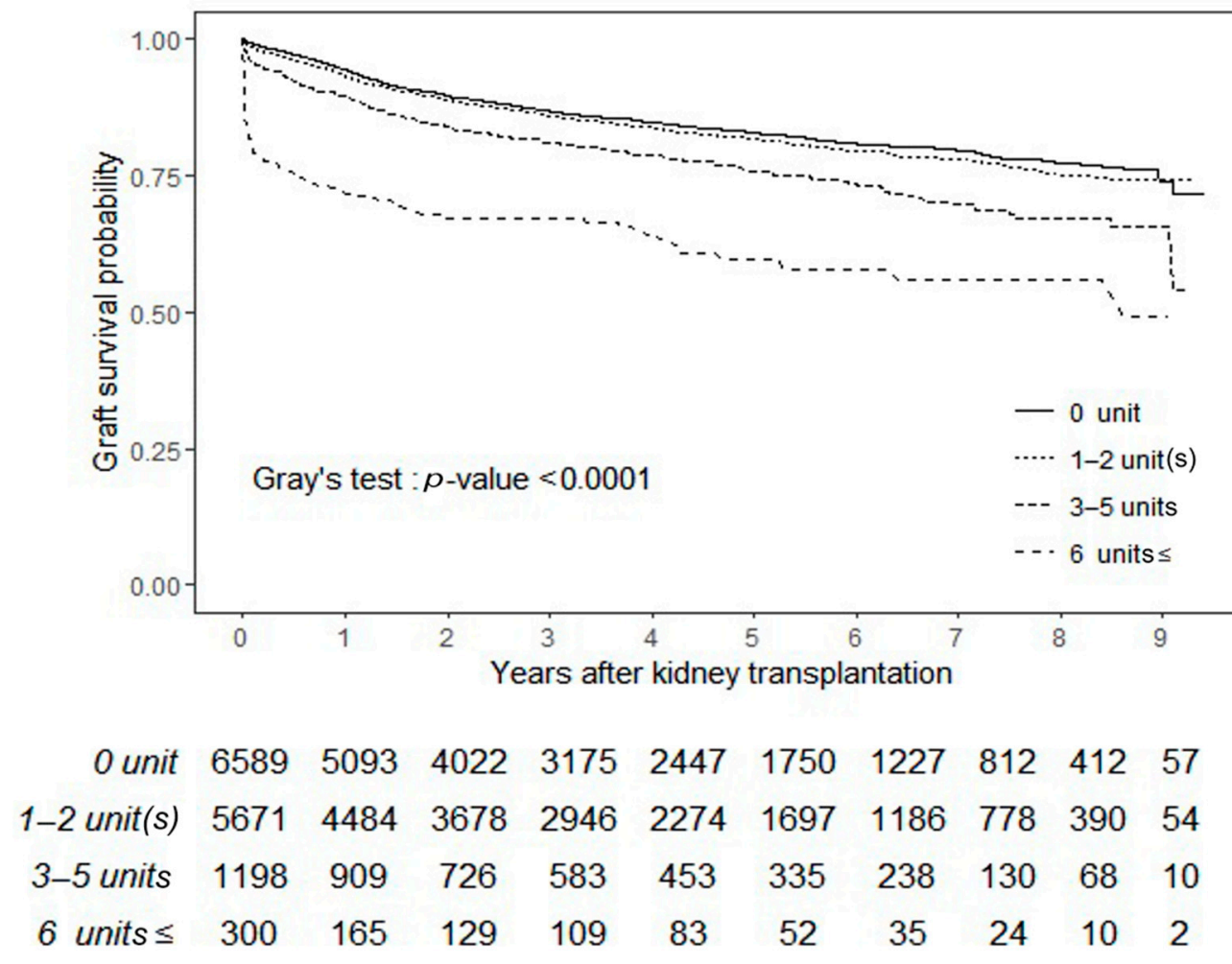

Figure 1. Death censored graft survival rate according to the amount of perioperative RBC transfusion. Graft survival rates were higher in patients who received less RBC transfusion (Fine and Gray model, $p<0.001$ ). Abbreviations: KT, kidney transplantation and RBC, red blood cell.

In the Cox proportional hazard model for all-cause mortality, adjusted HRs were higher in patients who received 6 or more units of RBC compared to patients who received 5 units or less (Table 4). Deceased donor KT, acute rejection, and delayed graft function were also associated with higher mortality. The long-term survival analysis of up to 10 years showed a higher probability of survival in patients who received less RBC transfusion (log-rank test $p<0.001$, Figure 2).

Table 4. Cox regression analysis for death after kidney transplantation.

\begin{tabular}{|c|c|c|c|c|c|c|}
\hline & \multicolumn{3}{|c|}{ Univariate Analyses } & \multicolumn{3}{|c|}{ Multivariable Analyses } \\
\hline & $\begin{array}{c}\text { Hazard } \\
\text { Ratio }\end{array}$ & $95 \%$ CI & $p$-Value & $\begin{array}{c}\text { Hazard } \\
\text { Ratio }\end{array}$ & $95 \%$ CI & $p$-Value \\
\hline \multicolumn{7}{|l|}{ Age } \\
\hline \multicolumn{7}{|l|}{$19-49$} \\
\hline $50-59$ & 2.59 & $2.14,3.14$ & $<0.001$ & 2.31 & $1.91,2.80$. & $<0.001$ \\
\hline$\geq 60$ & 5.27 & $4.29,6.47$ & $<0.001$ & 4.33 & $3.51,5.34$. & $<0.001$ \\
\hline \multicolumn{7}{|l|}{ Sex } \\
\hline Female & & & & & & \\
\hline Male & 1.24 & $1.05,1.46$. & 0.010 & 1.25 & $1.06,1.48$. & 0.009 \\
\hline Living donor kidney transplantation & & & & & & \\
\hline Deceased donor kidney transplantation & 2.23 & $1.90,2.62$ & $<0.001$ & 1.55 & $1.31,1.84$. & $<0.001$ \\
\hline \multicolumn{7}{|l|}{ Donor specific antibody } \\
\hline Present & 1.43 & $1.15,1.76$ & 0.001 & 0.93 & $0.74,1.16$ & 0.504 \\
\hline \multicolumn{7}{|l|}{ Induction treatment } \\
\hline Anti-thymocyte globulin & 2.68 & $1.57,4.54$ & $<0.001$ & 1.28 & $0.75,2.19$. & 0.367 \\
\hline Basiliximab & 1.70 & $1.03,2.79$ & 0.038 & 1.23 & $0.74,2.03$ & 0.419 \\
\hline Rituximab & & & & & & \\
\hline
\end{tabular}


Table 4. Cont.

\begin{tabular}{|c|c|c|c|c|c|c|}
\hline & \multicolumn{3}{|c|}{ Univariate Analyses } & \multicolumn{3}{|c|}{ Multivariable Analyses } \\
\hline & $\begin{array}{c}\text { Hazard } \\
\text { Ratio }\end{array}$ & $95 \%$ CI & $p$-Value & $\begin{array}{c}\text { Hazard } \\
\text { Ratio }\end{array}$ & $95 \% \mathrm{CI}$ & $p$-Value \\
\hline \multicolumn{7}{|l|}{ Acute rejection } \\
\hline Present & 1.53 & $1.21,1.94$ & $<0.001$ & 1.74 & $1.37,2.21$ & $<0.001$ \\
\hline \multicolumn{7}{|l|}{ Delayed graft function } \\
\hline Present & 15.05 & $12.17,18.62$ & $<0.001$ & 4.15 & $3.14,5.48$ & $<0.001$ \\
\hline \multicolumn{7}{|l|}{ Transfused red blood cell units } \\
\hline $1-2$ units & 1.55 & $1.27,1.89$ & $<0.001$ & 1.50 & $1.22,1.83$ & $<0.001$ \\
\hline $3-5$ units & 3.07 & $2.39,3.94$ & $<0.001$ & 2.43 & $1.87,3.15$ & $<0.001$ \\
\hline 6 units or more & 16.49 & $13.06,20.83$ & $<0.001$ & 6.81 & $5.03,9.22$ & $<0.001$ \\
\hline Elixhauser Comorbidity Index & 1.04 & $1.03,1.05$. & $<0.001$ & 1.02 & $1.01,1.03$ & $<0.001$ \\
\hline
\end{tabular}

Abbreviation: $\mathrm{CI}$, confidence interval.

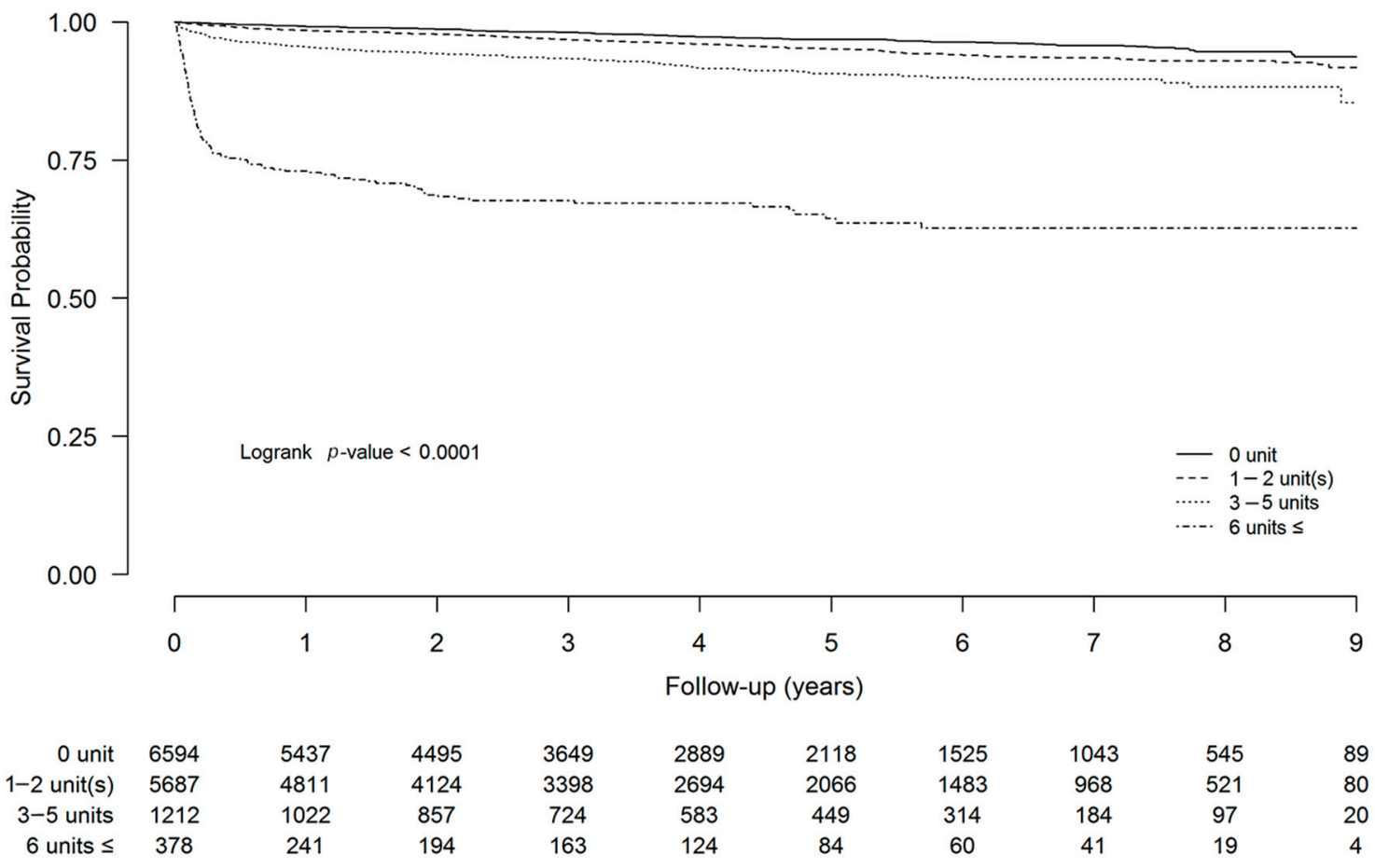

Figure 2. Patient survival according to the amount of perioperative RBC transfusion. Long-term survival analysis of up to 10 years after KT showed higher survival rates in patients who received less RBC transfusion (log-rank test $p<0.001)$. Abbreviations: KT, kidney transplantation and RBC, red blood cell.

\section{Discussion}

Our results suggest that 3 or more units of RBC transfusion during the perioperative period for KT may be associated with an increased risk of graft failure after KT. The association between perioperative RBC transfusion and renal allograft survival in a nationwide large cohort may suggest the importance of adequate management for anemia in ESRD patients waiting for KT.

As the incidence and prevalence of chronic kidney disease (CKD) grows, the number of patients on the waiting list for KT is also increasing. Death-censored kidney allograft survival has increased steadily over the past decade in both adult and pediatric patients [12]. The Scientific Registry of Transplant Recipients reported a 10-year overall graft survival in 
both living and deceased donors of approximately 70 to $80 \%$, which indicated significant progress from the previous 35 to $40 \%$ [1,2]. Our data showed a similar 5-year renal allograft survival of $82 \%$.

Many factors affect the long-term outcome of KT, which is often defined as patient death or renal dysfunction leading to graft loss requiring dialysis [13]. Donor age and HLA matching were well-known prognostic factors of the renal allograft outcome $[14,15]$. Key recipient factors include age, disease recurrence, HLA matching, HLA immunization, ethnic background, time on dialysis, and cardiovascular comorbidities [13]. To analyze the association between the RBC transfusion, renal outcome, and patient survival after KT, multivariable analyses were performed by adjusting for well-known prognostic factors such as age, donor type, and major comorbidities.

The NHI program is the universal healthcare coverage system in Korea. The NHIS provides healthcare insurance to more than $97 \%$ of the population in Korea through the NHI program and is the single payer of the NHI program. The remaining $3 \%$ of the population with the lowest income are supported by the Medical Aid program [16]. The broad inclusiveness and completeness of the database is one of the main strengths of our study. In addition, concrete outcomes such as graft failure and mortality were used as end points.

Studies prior to the 1980s suggested that pre-transplant RBC transfusion may improve allograft survival $[17,18]$. Based on these findings, at the time many transplant centers routinely transfused patients prior to KT [5]. Subsequently, the practice of pre-transplant RBC transfusion decreased as the risk of immune sensitization and potential infection outweighed the benefits of transfusion, especially with advances in immunosuppressant drugs, leading to improved outcomes without pretransplant transfusion [19]. The benefit of the restrictive transfusion strategy has been shown in various conditions due to the association between liberal transfusion strategies and adverse outcomes including infection, acute respiratory distress syndrome, multi-organ dysfunction, and mortality [6].

The impact of transfusion in KT has not been studied extensively and the results of the few studies that evaluated the impact of transfusion on renal allograft outcomes were inconsistent. Transfusion prior to KT was recently reported to be associated with the development of anti-HLA antibodies in patients with no previous organ transplantation or pregnancy [20]. In contrast, although analyzed using a less sensitive assay for antibody detection, transfusion in patients with a functioning graft under maintenance immunosuppression was not associated with the de novo formation of HLA antibodies [11]. However, one recent study using modern sensitive immunological tests for antibody detection demonstrated that overall incidences of DSAs and antibody-mediated rejection were significantly higher in KT patients who received transfusion after transplantation [10].

Although, our study focused on the effect of perioperative RBC transfusion on the renal outcome, transfusion after discharge from the admission for KT may have affected allograft outcomes. However, previous studies have shown that most blood transfusion (70 to $90 \%$ ) occurred during the perioperative hospital admission period [10,11]. In both previous studies and our study, most patients received less than 3 units of RBCs $[10,11,21]$. In addition, considering that it takes approximately 28 days for the renal allograft to produce erythropoietin after KT [22] and that DGF or chronic allograft dysfunction may cause the suppression of erythropoietin production, transfusion long after KT is likely to be a consequence of graft dysfunction rather than a cause.

Our data suggests that perioperative transfusion may have negative effects on longterm graft survival after kidney transplantation. The Renal Association Clinical Practice Guidelines suggest that hemoglobin levels should be maintained in the range of $10-12 \mathrm{~g} / \mathrm{dL}$ in CKD patients with ESA therapy [23]. Maintaining the hemoglobin level preoperatively with optimal ESA therapy could be the first step to minimize perioperative blood transfusion. Novel drugs such as hypoxia-inducible factor stabilizers, maintaining normothermia for optimal hemostasis, and the application of modern cell salvage technologies for rapid autologous transfusion may be additional strategies to avoid allogenic blood transfusion. 
Avoiding unnecessary blood tests during the perioperative period may also contribute to minimizing transfusion [24].

Patients undergoing deceased donor KT recipients showed a higher transfusion rate compared to living donor KT recipients (63\% vs. $50 \%)$, which is consistent with the findings of previous studies [11]. Given the unpredictable timing of deceased donor organs, achieving and maintaining optimal hemoglobin levels before KT may have been difficult in deceased donor KT. An additional explanation may be that the discontinuation of antiplatelet therapy prior to KT may not be feasible in the deceased donor KT setting [25]. Considering the higher risk of DGF in deceased donor KT [26], especially with extended criteria donors [27], prolonged insufficient erythropoietin production of DGF may have increased the need for transfusion after transplantation.

This study has several limitations that requires consideration. First, due to the nature of administrative data, the NHIS database lacks several clinically relevant variables including laboratory data and detailed clinical information. Although data regarding perioperative bleeding complications were added to compensate for the lack of hemoglobin levels, comparing patients with similar hemoglobin levels may have provided a clearer picture. However, we believe that the clinical implications of our study are still considerable as specific clinically relevant outcomes were analyzed, adjusting for major comorbidities and immunologic factors. Second, data regarding the types of transfused RBCs such as leukocyte depleted or radiated RBCs were not available in our analyses. Although leukocyte depleted RBCs are commonly used to prevent alloimmune sensitization, HLA class I molecules are expressed constitutively on erythrocytes even though their expression levels are low. The content of HLA molecules within leukocyte depleted RBCs is sufficient to induce HLA class I sensitization. Leukodepletion of blood products is not sufficient to prevent the risk of allosensitization [28,29]. Third, institutional differences in surgical techniques and RBC transfusion practices might also have affected the results as confounders. Recognizing that protocols for KT and transfusion have been established and standardized by several leading transplantation centers, the impact of the variation may be considered as minimal. Fourth, the underlying diseases causing allograft failure could not be identified using the NHIS database. Both alloimmune mechanisms and non-alloimmune injuries such as recurrent primary diseases contribute to allograft failure [30]. Alloimmune responses are known to play substantial roles in the progression of allograft failure even in patients with recurrent primary disease [31]. Although the main cause of graft failure was not available in our study, alloimmune processes provoked by RBC transfusion may have contributed to graft failure. However, future studies using histologic data and serial serum DSA levels are required to confirm the long-term immunological effects of RBC transfusion.

Despite these limitations, our study provides some important clinical implications. Our study is the first large scale study to investigate the relationship between perioperative RBC transfusion and graft survival after KT. In addition, selection bias was minimized by using the NHIS database, which includes nearly all KT operations performed in the recent 10 years in Korea. In conclusion, KT patients who received more RBC transfusion over 2 units during the perioperative period showed lower graft survival compared to those who received no transfusion or less than 3 units.

Author Contributions: K.L., drafting of the manuscript, analysis and interpretation of data, and critical revision; S.L., drafting of the manuscript, analysis and interpretation of data, and critical revision; E.J.J., acquisition of data, analysis and interpretation of data, and statistics; G.H.K.: acquisition of data, analysis and interpretation of data, and statistics; S.Y., critical revision; M.L., critical revision; H.R.J., study concept and design, acquisition of data, analysis and interpretation of data, drafting of the manuscript, and critical revision; and H.G.R., study concept and design, acquisition of data, analysis and interpretation of data, drafting of the manuscript, and critical revision. All authors have read and agreed to the published version of the manuscript.

Funding: This work was supported by the Research Resettlement Fund for the new faculty of Seoul National University (800-20180443). 
Institutional Review Board Statement: The study was approved by the Institutional Review Board of Seoul National University Hospital (protocol code 1708-061-877).

Informed Consent Statement: Patient consent was waived due to the retrospective and descriptive nature of this study and de-identified data without any personal information.

Data Availability Statement: Restrictions apply to the availability of these data. Data were obtained from National Health Insurance Service (NHIS) and are available from the authors with the permission of NHIS.

Acknowledgments: Hye Ryoun Jang was supported by the National Research Foundation of the Republic of Korea (grant numbers: 2016R1A2B4008235 and 2019R1A2B5B01069346) and the Korea Health Technology R\&D Project through the Korea Health Industry Development Institute (KHIDI), funded by the Ministry of Health and Welfare, Republic of Korea (grant number: HC20C0085). Kyungho Lee was supported by the Korea Health Technology R\&D Project through the Korea Health Industry Development Institute (KHIDI), funded by the Ministry of Health and Welfare, Republic of Korea (grant number: HI19C1337).

Conflicts of Interest: The authors declare no conflict of interest.

$\begin{array}{ll}\text { Abbreviations } \\ \text { CI } & \text { confidence interval } \\ \text { CKD } & \text { chronic kidney disease } \\ \text { DDKT } & \text { deceased donor kidney transplantation } \\ \text { DGF } & \text { delayed graft function } \\ \text { DSA } & \text { donor specific antibody } \\ \text { ESA } & \text { erythropoiesis-stimulating agent } \\ \text { ESRD } & \text { end-stage renal disease } \\ \text { HLA } & \text { human leukocyte antigen } \\ \text { HR } & \text { hazard ratio } \\ \text { ICU } & \text { intensive care unit } \\ \text { KT } & \text { kidney transplantation } \\ \text { NHI } & \text { National Healthcare Insurance } \\ \text { NHIS } & \text { National Healthcare Insurance Service } \\ \text { OR } & \text { odds ratio } \\ \text { RBC } & \text { red blood cell } \\ \text { sHR } & \text { subdistribution hazard ratio }\end{array}$

\section{References}

1. Sam, R.; Leehey, D.J. Improved graft survival after renal transplantation in the United States, 1988 to 1996. N. Engl. J. Med. 2000, 342, 1837-1838.

2. Hart, A.; Smith, J.M.; Skeans, M.A.; Gustafson, S.K.; Wilk, A.R.; Castro, S.; Foutz, J.; Wainright, J.L.; Snyder, J.J.; Kasiske, B.L.; et al. OPTN/SRTR 2018 Annual data report: Kidney. Am. J. Transplant. 2020, 20, 20-130. [CrossRef]

3. Coemans, M.; Susal, C.; Dohler, B.; Anglicheau, D.; Giral, M.; Bestard, O.; Legendre, C.; Emonds, M.P.; Kuypers, D.; Molenberghs, G.; et al. Analyses of the short- and long-term graft survival after kidney transplantation in Europe between 1986 and 2015. Kidney Int. 2018, 94, 964-973. [CrossRef] [PubMed]

4. Meier-Kriesche, H.U.; Schold, J.D.; Srinivas, T.R.; Kaplan, B. Lack of improvement in renal allograft survival despite a marked decrease in acute rejection rates over the most recent era. Am. J. Transplant. 2004, 4, 378-383. [CrossRef] [PubMed]

5. Pfaff, W.W.; Howard, R.J.; Scornik, J.C.; Day, C.; Renderer, J.; Scott, J.; Fennel, R.S.; Peterson, J.C.; Salomon, D.R.; Patton, P.R. Incidental and purposeful random donor blood transfusion. Sensitization and transplantation. Transplantation 1989, 47, 130-133. [PubMed]

6. Simon, T.L.; Edward, J.M.; Snyder, L.; Solheim, B.G.; Ronald, G.S. Trauss. Rossi's Principles of Transfusion Medicine, 5th ed.; John Wiley \& Sons: Chichester, UK, 2016.

7. Terasaki, P.I.; McClelland, J.D.; Yuge, J.; Cecka, J.M.; Gjertson, D.W.; Takemoto, S.; Cho, Y.W. Advances in kidney transplantation: 1985-1995. Clin. Transpl. 1995, 9, 487-501.

8. Carpenter, C.B. Blood transfusion effects in kidney transplantation. Yale J. Biol. Med. 1990, 63, 435-443. [PubMed]

9. Macdougall, I.C. Novel erythropoiesis-stimulating agents: A new era in anemia management. Clin. J. Am. Soc. Nephrol. 2008, 3, 200-207. [CrossRef] 
10. Ferrandiz, I.; Congy-Jolivet, N.; Del Bello, A.; Debiol, B.; Trebern-Launay, K.; Esposito, L.; Milongo, D.; Dorr, G.; Rostaing, L.; Kamar, N. Impact of early blood transfusion after kidney transplantation on the incidence of donor-specific anti-HLA antibodies. Am. J. Transplant. 2016, 16, 2661-2669. [CrossRef]

11. Scornik, J.C.; Schold, J.D.; Bucci, M.; Meier-Kriesche, H.U. Effects of blood transfusions given after renal transplantation. Transplantation 2009, 87, 1381-1386. [CrossRef]

12. Hart, A.; Smith, J.M.; Skeans, M.A.; Gustafson, S.K.; Wilk, A.R.; Robinson, A.; Wainright, J.L.; Haynes, C.R.; Snyder, J.J.; Kasiske, B.L.; et al. OPTN/SRTR 2016 Annual data report: Kidney. Am. J. Transplant. 2018, 18, 18-113. [CrossRef]

13. Legendre, C.; Canaud, G.; Martinez, F. Factors influencing long-term outcome after kidney transplantation. Transpl. Int. 2014, 27, 19-27. [CrossRef] [PubMed]

14. Alexander, J.W.; Bennett, L.E.; Breen, T.J. Effect of donor age on outcome of kidney transplantation. A two-year analysis of transplants reported to the United Network for Organ Sharing Registry. Transplantation 1994, 57, 871-876. [CrossRef]

15. Süsal, C.; Opelz, G. Current role of human leukocyte antigen matching in kidney transplantation. Curr. Opin. Organ Transplant. 2013, 18, 438-444. [CrossRef] [PubMed]

16. Song, S.O.; Jung, C.H.; Song, Y.D.; Park, C.Y.; Kwon, H.S.; Cha, B.S.; Park, J.Y.; Lee, K.U.; Ko, K.S.; Lee, B.W. Background and data configuration process of a nationwide population-based study using the korean national health insurance system. Diabetes Metab. J. 2014, 38, 395-403. [CrossRef]

17. Opelz, G.; Terasaki, P.I. Improvement of kidney-graft survival with increased numbers of blood transfusions. N. Engl. J. Med. 1978, 299, 799-803. [CrossRef]

18. Vincenti, F.; Duca, R.M.; Amend, W.; Perkins, H.A.; Cochrum, K.C.; Feduska, N.J.; Salvatierra, O. immunologic factors determining survival of cadaver-kidney transplants. N. Engl. J. Med. 1978, 299, 793-798. [CrossRef] [PubMed]

19. Sautner, T.; Gnant, M.; Banhegyi, C.; Wamser, P.; Götzinger, P.; Steininger, R.; Mühlbacher, F. Risk factors for development of panel reactive antibodies and their impact on kidney transplantation outcome. Transpl. Int. Off. J. Eur. Soc. Organ Transplant. 1992, 5, 116-120. [CrossRef]

20. Terasaki, P.I. Humoral theory of transplantation. Am. J. Transplant. 2003, 3, 665-673. [CrossRef]

21. Fidler, S.; Swaminathan, R.; Lim, W.; Ferrari, P.; Witt, C.; Christiansen, F.T.; D’Orsogna, L.J.; Irish, A.B. Peri-operative third party red blood cell transfusion in renal transplantation and the risk of antibody-mediated rejection and graft loss. Transpl. Immunol. 2013, 29, 22-27. [CrossRef]

22. Yabu, J.M.; Winkelmayer, W.C. Posttransplantation anemia: Mechanisms and management. Clin. J. Am. Soc. Nephrol. 2011, 6, 1794-1801. [CrossRef]

23. Mikhail, A.; Brown, C.; Williams, J.A.; Mathrani, V.; Shrivastava, R.; Evans, J.; Isaac, H.; Bhandari, S. Renal association clinical practice guideline on Anaemia of Chronic Kidney Disease. BMC Nephrol. 2017, 18, 1-29. [CrossRef] [PubMed]

24. Scornik, J.C.; Meier-Kriesche, H.U. Blood transfusions in organ transplant patients: Mechanisms of sensitization and implications for prevention. Am. J. Transplant. 2011, 11, 1785-1791. [CrossRef]

25. Marzouk, K.; Lawen, J.; Kiberd, B.A. Blood transfusion in deceased donor kidney transplantation. Transplant. Res. 2013, 2, 4. [CrossRef] [PubMed]

26. Schroppel, B.; Legendre, C. Delayed kidney graft function: From mechanism to translation. Kidney Int. 2014, 86, 251-258. [CrossRef] [PubMed]

27. Aubert, O.; Kamar, N.; Vernerey, D.; Viglietti, D.; Martinez, F.; Duong-Van-Huyen, J.P.; Eladari, D.; Empana, J.P.; Rabant, M.; Verine, J.; et al. Long term outcomes of transplantation using kidneys from expanded criteria donors: Prospective, population based cohort study. BMJ 2015, 351, h3557. [CrossRef] [PubMed]

28. Balasubramaniam, G.S.; Morris, M.; Gupta, A.; Mesa, I.R.; Thuraisingham, R.; Ashman, N. Allosensitization rate of male patients awaiting first kidney grafts after leuko-depleted blood transfusion. Transplantation 2012, 93, 418-422. [CrossRef] [PubMed]

29. Scornik, J.C. Leukoreduced blood and sensitization of organ transplant candidates. Transfusion 2012, 52, 1838-1839. [CrossRef]

30. Burton, H.; Iyamu Perisanidou, L.; Steenkamp, R.; Evans, R.; Mumford, L.; Evans, K.M.; Caskey, F.J.; Hilton, R. Causes of renal allograft failure in the UK: Trends in UK Renal Registry and National Health Service Blood and Transplant data from 2000 to 2013. Nephrol. Dial. Transplant. 2019, 34, 355-364. [CrossRef]

31. Van Loon, E.; Bernards, J.; Van Craenenbroeck, A.H.; Naesens, M. The causes of kidney allograft failure. Transplantation 2020, 104, e46-e56. [CrossRef] 